\title{
Blockchain Technologies from the Consumers' Perspective: What Is There and Why Should Who Care?
}

\author{
Manuel Schlegel \\ University of Zurich \\ manuel.schlegel@uzh.ch
}

\author{
Liudmila Zavolokina \\ University of Zurich \\ zavolokina@ifi.uzh.ch
}

\author{
Gerhard Schwabe \\ University of Zurich \\ schwabe@ifi.uzh.ch
}

\begin{abstract}
The blockchain, the ledger that underlies the famous cryptocurrency Bitcoin, has huge implications for many industries. There have been various papers dedicated to research how blockchain technology will transform businesses and industries. However, current research lacks an overview of what the blockchain implies for the biggest stakeholder of these businesses and industries: consumers. This paper aims to provide an overview of how the blockchain affects consumers. We conduct a systematic literature review and enrich it with interview-based knowledge from blockchain experts to show how blockchain technology changes business sectors, name affected consumers in these sectors, derive implications for these consumers and list existing as well as currently emerging blockchainbased products and services. Finally, we warn of the technical, institutional and human challenges and manifold pitfalls blockchain technology must overcome to gain widespread adaptation among consumers.
\end{abstract}

\section{Introduction}

Bitcoin [1], the famous first and most popular cryptocurrency, has received huge amounts of attention in the last years in the financial industry. However, the blockchain, which is the ledger that underlies the cryptocurrency, has not only the potential to redefine financial services, but disrupt many other business sectors as well. The scientific community and many firms show great interest for blockchain. The reason for this interest stems from the properties blockchain provides: it offers trust, data integrity, security and anonymity without having to rely on a central third-party organization. However, the research currently lacks an overview of what the blockchain implies for consumers. It is important to identify which topics have already been studied. Thus, this paper aims to provide an overview of how the blockchain affects consumers. Accordingly, we state the following research questions:

$R Q$ 1: What blockchain-based solutions exist for consumers?
$R Q$ 2: Who are targeted consumers and how are they affected by blockchain-based solutions?

Mainly we are interested in the effects of blockchain on the end consumers of products and services. In this work, "consumer" refers to clients on the $\mathrm{B} 2 \mathrm{C}$ (Business-To-Consumer) and the $\mathrm{C} 2 \mathrm{C}$ (Consumer-ToConsumer) end. To answer the research questions, we conduct a structured literature review. In the overview of our work, we name different sectors where blockchain solutions are either available today or in development. For each sector, we identify targeted consumers and how they are affected. This overview assists other researchers and practitioners by identifying possible future research areas and open questions. It also helps researchers to quickly get an overview of the research state of blockchain.

The paper is structured as follows: in section 2, we discuss how digitalization affects consumers, introduce blockchain and explain the idea of smart contracts. In section 3, we describe the systematic literature review and the conducted interviews, and present the results in section 4 . We discuss the findings in section 5 and in section 6 we draw conclusions, show limitations of our study and give an outlook for future research.

\section{Relevant Literature}

\subsection{How Digitalization affects Consumers}

Consumer behavior is defined as the study of human responses to products and services [2]. It discusses how individuals make decisions to spend resources on consumption related items [2]. Recent advances in digital technologies are affecting significant and unprecedented changes in many aspects of our social and economic lives [3]-[5], which in turn fundamentally alter the way we communicate, create and consume [3], [6], [7]. This phenomenon is known as "digitalization". Digitalization is thought to greatly affect the business world, private lives and society [8], [9].

The framework of [9] is based on a state of the art literature review that identifies and categorizes the benefits and value drivers of digitalization. According to [9], the main value drivers of digitalization are efficiency and customer experience. Whereas efficiency is 
important for the competitive advantage among companies, customer experience primarily affects consumers. Consumers are more powerful because of digital technologies [3] and thus, firms likely will improve their customer experience to react to the empowered consumers [10]. The improved customer experience of digitalization is based on effects in the following categories: customer interaction convenience, customer tailored solutions, innovative products and services, and product and service quality [9]. With the ongoing digitalization and new emerging technologies such as the blockchain, consumers can and should expect improvements in these four main categories.

\subsection{Blockchain Technology and Smart Con- tracts}

Blockchain is the operation mechanism, underlying Bitcoin, and has promised lots of potential [11]. From a technological point of view, the blockchain can be defined as a decentralized shared ledger that uses chronological, encrypted and chained blocks to store verifiable and synchronized data across a peer-to-peer (P2P) network [12]. The key characteristics of blockchain models can be summarized as follows: trust, immutability, decentralization, security, chronological data, collective maintenance and programmability [12], [13]. Blockchain offers trust as it lets people collaborate with each other without them having to establish a trust relationship between each other. Instead, they only have to trust the blockchain itself, as the blockchain protocol establishes a set of rules that ensure the integrity of the data being exchanged without having to use a trusted third party [14]. It provides immutability, as data on the blockchain is nearly impossible to remove or modify. It is decentralized because the blockchain does not exist on just one single computer. Instead, it is mirrored and distributed on many different computers. It grants security as the data stored on the blockchain is usually heavily encrypted. Chronological data is guaranteed because the blockchain not only permanently records data, but also links the different blocks in chronological order. Because the blockchain is distributed, maintenance mostly occurs through collective decisions. Finally, it grants programmability as one can not only store data in the blocks, but also code.

Furthermore, the number of possible blockchain applications explodes with smart contracts. Smart contracts are a group of self-verifying, self-executing and self-enforcing state rules that are stored on and secured by the blockchain itself [12]. This corresponds to the programmability characteristic mentioned before. The main idea is that two or more parties form a contract, define all terms within this contract and then cryptographically sign the contract and broadcast it to the P2P network for verification [12], [15]. When the pre- defined conditions are triggered, smart contracts will self-execute and trigger a corresponding response action based on the agreement without any intervention of third parties [12]. The concept of smart contracts, especially in combination with the Internet of Things (IoT), opens huge rooms for innovations. However, it is not clear what these innovations mean for consumers. There are a few studies outlining research agenda and identifying challenges for research (e.g. [16] or [17]). These discuss challenges posed by blockchain from different perspectives (e.g. technical) and call for further investigation on consumer's behavior.

\section{Methodology}

As the blockchain can find use in a vast amount of areas, we performed a systematic literature review [18] to gather, summarize and categorize current blockchain literature (see process in Figure 1). For this purpose, a keyword search was conducted. Keywords were defined as follows: "(Blockchain Consumer) OR (Blockchain Consumers)" and "(Blockchain Application) OR (Blockchain Applications)". The search term "consumer(s)" was added to stress relevance to consumers. The search term "application(s)" was chosen as most publications about blockchain are written from the perspective of businesses. Naturally, results of the keyword "application(s)" were mostly written from the business side. However, by reading these articles we were able to infer conclusions for consumers. Only documents with a publication year after 2008 were considered, to make sure the literature was up to date.

Thus, in a first step, the search terms were applied to Google Scholar, AIS Electronic Library (AISeL) and IEEEXplore on the 13th of January 2017. AISeL returned respectively 23 and 28 results for the queries, while IEEEXplore showed respectively 4 and 22 results. Google Scholar yielded over 2’000 results for both search terms, sorted by relevance. Because of the large number of results in Google Scholar, for each term the first most relevant (in terms of Google Scholar search [19], [20]) 50 results were considered for analysis. Searching for further 50 articles confirmed that they are duplicates or discuss the same blockchain applications. However, we should admit, that Google Scholar's ranking algorithm heavily relies on a high number of citations [19]. This introduces a certain bias by finding the papers which are already well-known and hiding the very new ones [19]. As there are not that many results in the other main sources, all results from AISeL and IEEEXplore were considered. This sampling scheme was applied in order to get a global picture of what the current blockchain research looks like. Altogether, the first step retrieved a total of 177 papers. In a second step, the papers were screened 
based on their titles and abstracts. All studies that were not relevant to the blockchain topic were excluded, as well as papers that were not written in English. After this step, 65 papers remained. The reason for the high amount of removals (112) lies in the fact that a lot of papers were not directly related to the research topic. In a third step, all papers were merged together in one collection. In a fourth step, duplicates were removed. This resulted in a count of 53 papers. In a fifth step, the papers were analyzed based on their full text contents. Only papers that both describe the blockchain and allow inference about how blockchain affects consumers were accepted. In this step, 32 papers were removed as they were not directly related to how blockchain affects consumers. This left us with the 21 final papers.

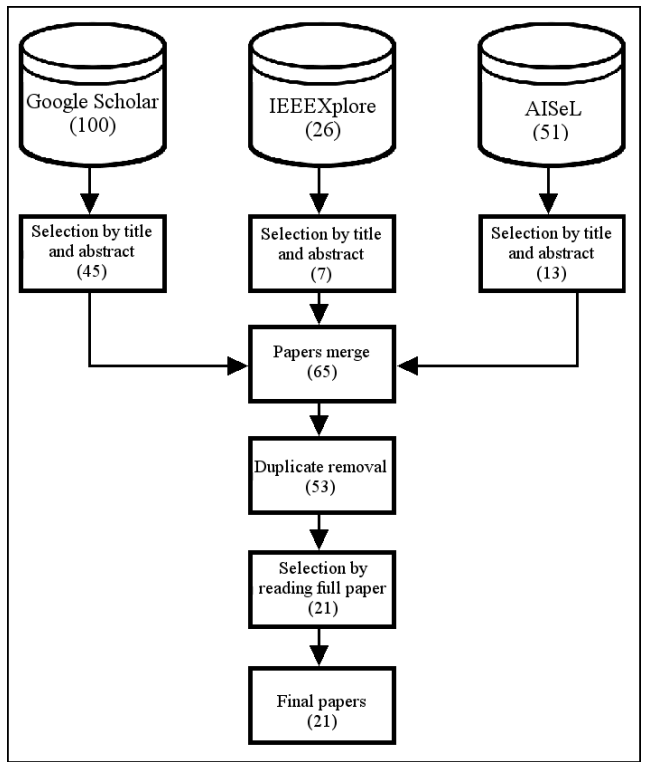

Figure 1. Search and selection process of the final papers

To analyze the final papers we applied content analysis. Content analysis is appropriate to describe a real-world phenomenon that has been hardly documented by now [21]. Coding of the data was conducted by a junior researcher (one year experience in IS research) under the supervision of a more experienced one (three years' experience in IS research) to ensure the consistency of the coding scheme. During the coding process, the researchers aimed to identify (1) blockchain-based solutions and their state (in development / existing); (2) (sub-)sectors, to which solutions belong to; (3) targeted consumers; (4) effects on these consumers based on parts of the framework of [9]. The framework was chosen as it is an accurate and extensive framework based on a sound systematic literature review with a large sample size.

Finally, to ensure correctness and validity of the collected results and categorization of the blockchain application areas, semi-structured interviews with three blockchain experts (one junior researcher with one year experience in blockchain research, one senior researcher with 15 years' experience in IS research, one industry expert who is a managing partner in a Swiss-based independent economic consultancy since 2008) were conducted. Similar to the literature analysis, we noticed that the interviewees gave similar feedback to the categorization and pointed out the same applications with their influence on consumers. Therefore, we stopped at three interviews. However, there might be new insights which could be brought up by other types of interviewees (e.g. blockchain developers, end consumers). These interviews were recorded and analyzed with the focus on blockchain-based solutions and their state (in development / existing), categorization of blockchain (sub-) sectors, targeted consumers and effect of the technology on them. Furthermore, the experts were asked to think about other areas and applications of blockchain, which go beyond the presented results (based on the literature search - see Table 1), and to critically reflect on challenges which technology pose to end consumers. These are further concluded in the "Discussion".

\section{Results}

In this section, we present the results of our literature analysis. For the final papers, information about their publication year, country of origin based on the place of publication and publication year were collected. Furthermore, we tracked for each paper to which sectors and subsectors it belongs to. These summary statistics can be found in Figure 2. Panel a) shows the publication year of the final papers. Interestingly, all papers were published after the year 2013. This can be explained as blockchain is a novel research area [16]. The results suggest a strong trend towards more published papers about blockchain every year. The low amount of published papers in 2017 (4) is due to the date the literature analysis was performed, which was the 13th of January 2017. If one takes into account that in only 13 days a total of 4 papers were published, it seems likely that the amount of publications in the entire year of 2017 will overtake the one of 2016 (12). Panel b) shows the geographic distribution of the final papers, which reveal that the US (38\%) is the location where most papers were published. Switzerland (14\%) is the second most popular country, while the third place is held by papers whose country of publication could not have been determined (10\%). Panel c) shows the amount of times each sector was mentioned in the final papers. The financial sector $(33 \%)$ is a primary focus of the research, with most papers dedicated to it. Records management (25\%) is the second most popular sector and supply chain $(20 \%)$ is located in third 
place. Panel d) shows the amount of times each subsec-

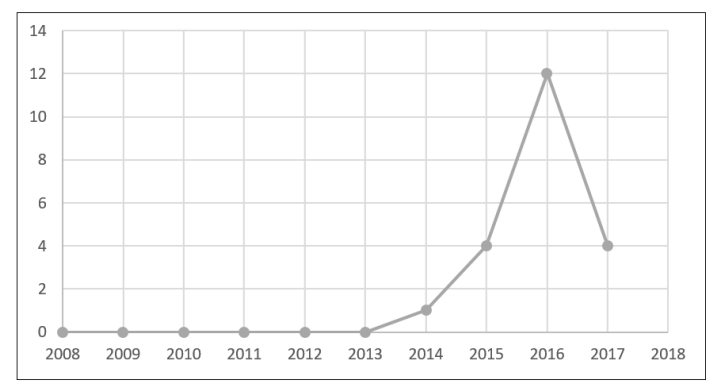

a) Publication year of the final papers

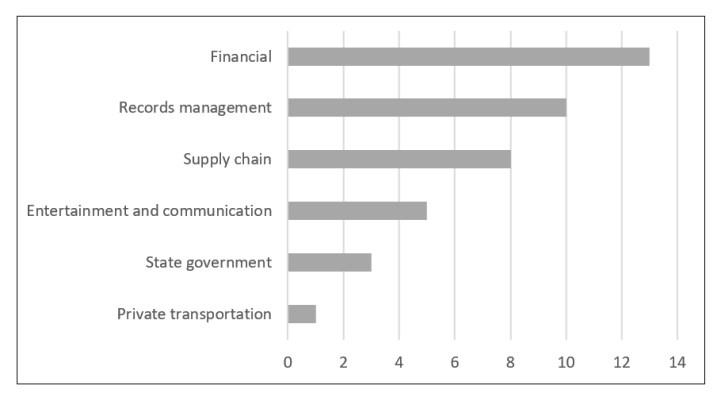

c) Sectors of the final papers tor was mentioned in the final papers.

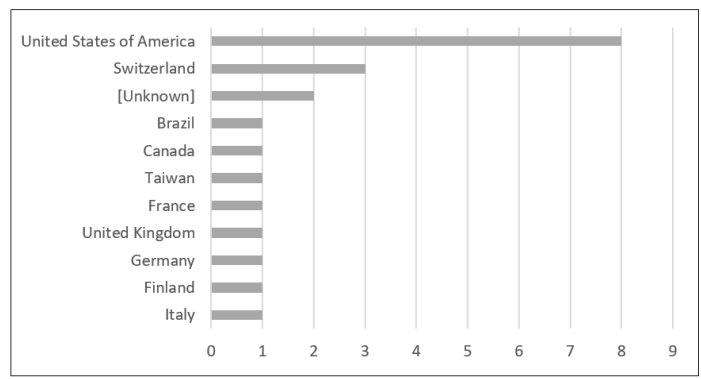

b) Geographic distribution of the final papers

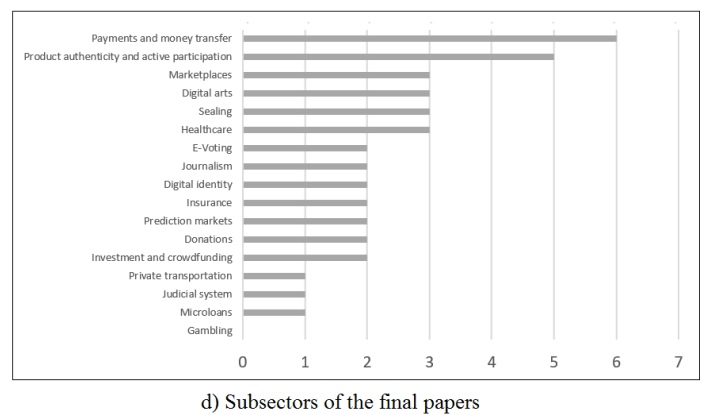

Figure 2. Summary statistics of the final papers

Similarly to the results of Panel c), Payments and money transfer $(15 \%)$ which belongs to the financial sector was referenced the most often. Marketplaces $(8 \%)$ are also a popular topic, just like sealing ( $8 \%$ ) and e-voting $(8 \%)$. The reason why gambling $(0 \%)$ does not show in the graph is because the sector was only mentioned in the interviews, but not in any of the final papers. For both panel c) and d) it is important to note that some final papers referenced multiple sectors respectively subsectors. In this case, all references were counted.

Following the results of the literature review, for each sector we describe current challenges and issues, explain how blockchain aims to solve these problems and what this means for consumers, and investigate where there are already working or emerging solutions. The targeted consumers of these solutions are mentioned. The effects on consumers are described as "customer interaction convenience", "customer tailored solutions", "innovative products and services" or "product and service quality" based on the key effects identified in the study from [9]. This is because we found that for nearly all results, only positive effects on consumers are named, which is why the framework from [9] is fitting to summarize these effects. To differentiate between actual effects, based on active solutions, and predicted implications, we mark predictions with stars in our results table. Table 1 shows the overview of sectors and sub-sectors of blockchain-based solutions, targeted consumers and effects on them. Further, we give detailed description of the top ten most referenced sub-sectors (due to space limitations, the rest of sub-sectors are characterized in Table 1), and summarize the results on sectors.

\subsection{Financial}

The financial sector is one of the most referenced sectors in the final papers. Blockchain has multiple effects for consumers. First of all, it allows money of any size (fractions of a cent or billions) and type (donations, payments, investments) to be sent nearly instantly across the globe with minimal fees. It also enables new ways to purchase financial products and allows for global prediction markets.

4.1.1 Payments and money transfer. The payments industry can be regarded as the center of innovations around blockchain [22]. Banks rely on being the "trusted middle man", a business model that is being threatened by the emergence of blockchain cryptocurrencies. As a result, many banks have invested in blockchainrelated research to not be surprised by a disruption in their core business. Another part of this sector are remittances. Costly fees [23] and slow transaction processes plague these consumers. Finally, a sizeable percentage of the population in underdeveloped countries have no or only limited access to banking services [14]. Blockchain in the payments industry is being proposed as a solution for real-time payments between two parties with rapid settlement and without the need of requiring a bank account [22]. For remittances, blockchain offers an opportunity to design a low cost service [23] which operates at high speed. The same is 
Table 1. Blockchain-based solutions and their effect on targeted consumers

\begin{tabular}{|c|c|c|c|c|}
\hline Sector & Subsector & $\begin{array}{l}\text { Targeted con- } \\
\text { sumers } \\
\text { *: predicted }\end{array}$ & $\begin{array}{l}\text { Effect on targeted consumers } \\
\qquad * \text { : predicted }\end{array}$ & $\begin{array}{c}\text { Existing blockchain } \\
\text { solutions } \\
* \text { : in development }\end{array}$ \\
\hline \multirow{5}{*}{ 呇 } & $\begin{array}{l}\text { Payments and } \\
\text { money transfer }\end{array}$ & $\begin{array}{l}\text { Bank customers, } \\
\text { electronic pay- } \\
\text { ment users }\end{array}$ & $\begin{array}{l}\text { Product and service quality: } \\
\text { - online instant payments to be sent directly from one user to another } \\
\text { - enables low-cost and high-speed remittances } \\
\text { Customer tailored solutions: } \\
\text { - tokens that allow a distributed crypto-equity share exchange, per- } \\
\text { mitting holders of a token to earn interest } \\
\text { Innovative products and services: } \\
\text { - perform a range of actions from registering securities to securing } \\
\text { bank balances as well as mortgages } \\
\text { - distributed stock market for equity securities } \\
\text { Customer interaction convenience: } \\
\text { - Bitcoin exchange focusing on speed } \\
\end{array}$ & $\begin{array}{l}\text { Bitcoin [1], Stellar } \\
\text { [29], Blockstream } \\
\text { [28], Coinsetter [28], } \\
\text { Bitshares [30], Medi- } \\
\text { ci }^{*}[31] \text { and BitPesa } \\
{[32]}\end{array}$ \\
\hline & $\begin{array}{l}\text { Investment and } \\
\text { crowdfunding }\end{array}$ & $\begin{array}{l}\text { Investors, stock- } \\
\text { holders }\end{array}$ & $\begin{array}{l}\text { Innovative products and services: } \\
\text { - exchange of private equities } \\
\text { - blockchain crowdfunding where investors raise funds for startups }\end{array}$ & $\begin{array}{l}\text { NASDAQ's } \\
\text { chain.com }[28] \text { and } \\
\text { Starbase }^{*}[30][33]\end{array}$ \\
\hline & Microloans & Entrepreneurs & $\begin{array}{l}\text { Innovative products and services: } \\
\text { - transfer micro sizes of monetary funds globally }\end{array}$ & Bitcoin \\
\hline & Donations & $\begin{array}{l}\text { Donors, donation } \\
\text { recipients }\end{array}$ & $\begin{array}{l}\text { Innovative products and services: } \\
\text { - Bitcoin payments as charity and donor contributions }\end{array}$ & Sean's Outpost [30] \\
\hline & Prediction markets & Share traders & $\begin{array}{l}\text { Innovative products and services: } \\
\text { - prediction market which allows users to buy and sell shares based } \\
\text { on predictions of the probabilities that certain events will occur }\end{array}$ & $\begin{array}{l}\text { Augur }[28][34] \text { and } \\
\text { Gnosis }\end{array}$ \\
\hline \multirow{4}{*}{ 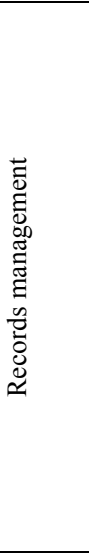 } & Healthcare & Patients & $\begin{array}{l}\text { Customer interaction convenience: } \\
\text { - a cheap and efficient alternative for storing patient health data } \\
\text { - platform to store and manage health information: customers can } \\
\text { choose to make their data available for medical research, in ex- } \\
\text { change they receive financial compensation }\end{array}$ & $\begin{array}{l}\text { Factom }[26] \text { and } \\
\text { healthbank }[35]\end{array}$ \\
\hline & Insurance & $\begin{array}{l}\text { Insurance cus- } \\
\text { tomers* }\end{array}$ & $\begin{array}{l}\text { Product and service quality*: } \\
\text { - improve the speed, convenience and security of insurance services }\end{array}$ & $B 3 i *[36]$ \\
\hline & Sealing & $\begin{array}{l}\text { Consumers with } \\
\text { desire for data } \\
\text { integrity }\end{array}$ & $\begin{array}{l}\text { Product and service quality: } \\
\text { - "stamp" emails or files, which simplifies certifying } \\
\text { - "blockchain notary" } \\
\text { - create proof of existence of any file using blockchain networks } \\
\text { - authorship certification and transfer of ownership } \\
\text { - sealing by storing hashes of documents in the Bitcoin blockchain } \\
\text { - decentralized book-keeping }\end{array}$ & $\begin{array}{l}\text { Stampery [28], } \\
\text { Viacoin, Block Nota- } \\
\text { ry [28], Ascribe [28], } \\
\text { Proof of Existence } \\
\text { [28], Factom and } \\
\text { Scorechain* }{ }^{[37]}\end{array}$ \\
\hline & Digital identity & $\begin{array}{l}\text { Consumers with } \\
\text { digital identities }\end{array}$ & $\begin{array}{l}\text { Innovative products and services: } \\
\text { - digital identities by registering the identities on Bitcoin } \\
\text { - give businesses and individuals control over their identities }\end{array}$ & $\begin{array}{l}\text { Onename [34] and } \\
\text { Civic* }\end{array}$ \\
\hline \multirow{3}{*}{ 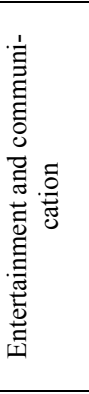 } & Digital arts & $\begin{array}{l}\text { Consumers of } \\
\text { digital arts }\end{array}$ & $\begin{array}{l}\text { Innovative products and services: } \\
\text { - transfer of ownership of digital work such as music, art and others } \\
\text { - user-generated meta data to solve the attribution problem } \\
\text { - royalty split for each work to be determined and executed automat- } \\
\text { ically using smart contracts, paying the owners/creators fair and just }\end{array}$ & $\begin{array}{l}\text { Ascribe }[34] \text { and } \\
\text { Mediachain }\end{array}$ \\
\hline & Gambling & Gamblers & $\begin{array}{l}\text { Product and service quality: } \\
\text { - online casino platform } \\
\text { - decentralized eSports reward platform for gamers }\end{array}$ & $\begin{array}{l}\text { SatoshiDice, VDice } \\
{[38] \text { and FirstBlood }} \\
{[39]}\end{array}$ \\
\hline & Journalism & $\begin{array}{l}\text { Magazine/article } \\
\text { readers }\end{array}$ & $\begin{array}{l}\text { Innovative products and services: } \\
\text { - social media platform to create, share and comment on content and } \\
\text { earn money through own content } \\
\text { - share censorship-resistant media content }\end{array}$ & $\begin{array}{l}\text { Steemit }[40] \text { and } \\
\text { DECENT* }[41][42]\end{array}$ \\
\hline \multirow{2}{*}{ 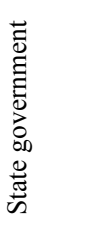 } & E-voting & Voters* & $\begin{array}{l}\text { Customer interaction convenience*: } \\
\text { - proxy voting } \\
\text { Product and service quality*: } \\
\text { - online-based voting platform with heavy cryptography to maintain } \\
\text { voter anonymity }\end{array}$ & $\begin{array}{l}\text { NASDAQ's E-Voting } \\
\text { in Estonia* [43], } \\
\text { FollowMyVote* and } \\
\text { BitCongress } * \text { [44] }\end{array}$ \\
\hline & Judicial system & $\begin{array}{l}\text { Participants of } \\
\text { legal discourse* }\end{array}$ & $\begin{array}{l}\text { Innovative products and services*: } \\
\text { - system, where justice is both transparent and self-sustained }\end{array}$ & CrowdJury*[45] \\
\hline 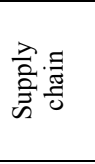 & Marketplaces & $\begin{array}{l}\text { Traders of mar- } \\
\text { ketplaces }\end{array}$ & $\begin{array}{l}\text { Customer tailored solutions: } \\
\text { - decentralized e-commerce marketplace, where anyone can either } \\
\text { set up a shop or be a client } \\
\text { - digital micro commerce marketplace: small chips can be embedded } \\
\text { into any connected device, which enable the device to buy and sell }\end{array}$ & $\begin{array}{l}\text { OpenBazaar and } 21 \\
{[26]}\end{array}$ \\
\hline
\end{tabular}




\begin{tabular}{|l|l|l|l|l|}
\hline & & digital goods and services in marketplaces & \\
\cline { 2 - 5 } & $\begin{array}{l}\text { Product authentici- } \\
\text { ty and active par- } \\
\text { ticipation }\end{array}$ & $\begin{array}{l}\text { Consumers of } \\
\text { valuable assets }\end{array}$ & $\begin{array}{l}\text { Customer interaction convenience: } \\
\text { - track products and protects valuable assets throughout their lifetime } \\
\text { journey } \\
\text { - blockchain anti-counterfeit solution for supply chain transparency }\end{array}$ & $\begin{array}{l}\text { Everledger [46], } \\
\text { Provenance and } \\
\text { BlockVerify [28] }\end{array}$ \\
\hline Private transportation & $\begin{array}{l}\text { Consumers with } \\
\text { need of mobility / } \\
\text { transportation* }\end{array}$ & $\begin{array}{l}\text { Innovative products and services*: } \\
\text { - smart contracts for self-driving vehicles } \\
\text { - blockchain-backed car wallet called eWallet, which allows users to } \\
\text { pay on-the-go and collect fees for car-sharing }\end{array}$ & $\begin{array}{l}\text { GM and Lyft } *^{*}[47] \\
\text { and UBS and ZF, } \\
\text { innogy SE* [48] }\end{array}$ \\
\hline
\end{tabular}

true for payments in general [22]. In addition, blockchain addresses the unbanked customer in the developing parts of the world and allows them to participate with almost zero costs [22]. Summarized, blockchain enables payments without the need of a central third party and allows them to be fast and cheap [22]. Among the targeted consumers are bank customers and electronic payments users in general. Based on the benefits for consumers in the paper from [9], customers will receive improvements in product and service quality, customer tailored solutions, innovative products and services, and customer interaction convenience.

\subsection{Records management}

In records management, blockchain's immutability characteristic brings forth many effects for consumers. It provides a cheap and secure way to store information while returning the ownership and control back to consumers. It also allows to store more precise data, in such a way that it is protected and tamper-proof.

4.2.1 Healthcare. Healthcare data is a valuable and important source of information. Sharing it is essential to make the healthcare system smarter and improve the quality of healthcare services [24]. However, healthcare data is neither owned nor controlled by patients, but instead scattered in different systems, which prevents data sharing and puts patient privacy at risk [24]. Using blockchain, patients can own, control and share their data easily and securely without having to risk a violation of their privacy [24]. Such systems can improve the intelligence of healthcare systems by giving all corresponding parties access to the exact data they need, while keeping patient data private at the same time [24]. Patients of healthcare organizations are the target audience. The main benefit is improved customer interaction convenience.

4.2.2 Insurance. When insurances are purchased, the resulting fee is linked with the associated risk. In order to properly calculate this risk, insurance companies need accurate data to make actuarial calculations [14]. Because insurance companies do not have accurate data about a specific consumer, the consumer gets generalized and can end up paying too much (or too little). Smart contracts are a way to improve the data insurance companies receive, and in return determine a more precise risk and fee for consumers.
For example, a motor insurance could be based on the state of both the car and also its driver [25]. Insurance customers are targeted and receive improved product and service quality.

4.2.3 Sealing. Sealing is the function devoted to securing the validity of information. This information can be crucial for individuals, for example it can be one's birth certificate or proof of land ownership. Developing countries often face mismanagement and corruption, but cannot afford or enforce infrastructure and processes to guarantee proper sealing of documents [26]. A decentralized platform based on blockchain is an interesting option for these governments [26]. Because the blockchain is tamper-proof, once ownership of a piece of land is registered, this information cannot be manipulated. This concept can be transferred from land ownership to many other areas, such as verification of documents or files. In general, all consumers with a desire for data integrity are the target audience for these solutions. Thanks to blockchain, they will experience improved product and service quality.

4.2.4 Digital identity. The centralization of digital identity-related information is of utmost political, legal and societal relevance in the digital age [27]. Currently, consumers do not control their data. Instead, big companies collect and herd consumer data in order to profit from it. Blockchain confers to digital identity a potentially revolutionary decentralization character [27]. Platforms built upon blockchain make it so one's digital identity cannot be controlled by a central institution [27], but instead only by the individual itself [26]. Using smart contracts, consumers could control their data and only reveal the information a partner needs to know, returning the power back to the consumers. Furthermore, consumers could use their digital identity as a reputation system by rating other users. Altogether, consumers with digital identities will be able to use innovative products and services.

\subsection{Entertainment and communication}

The entertainment and communication industry has gone through a lot of transformations in the past. With the introduction of blockchain, it may undergo another such transformation. Consumers will be able to directly support an artist or journalist whose content they appreciate, while being anonymous and free 
from censorship. Additionally, in the multi-billiondollar gambling industry, consumers will gain ways to play without the risk of getting cheated.

4.3.1 Digital arts. The music industry has strongly evolved in the last decade due to the growth of internet availability. However, the process by which music royalties are determined has always been complex, but the recent rise of new streaming services have made this issue even more complicated [28]. The artist is often the last one being paid [14] and it can take a long time until the first royalty check is received [14]. The blockchain can maintain a comprehensive and accurate database of music rights ownership information in a public ledger, making sure content creators are getting paid fairly [28]. Consumers of digital arts are targeted. They will have access to innovative products and services.

4.3.2 Journalism. Journalists are often pressured through the grip of state-controlled media [14]. They cannot cover politics freely and in some countries censorship through government is a permanent obstacle. The growth of journalism can be assisted by blockchain. Consumers can pay several cents to view an article that they are interested in [11], directly supporting the journalist. This encourages publishers to create more valuable content while gradually eliminating those with superficial content funded by advertising [11]. Due to the immutability and cryptographic properties of the blockchain, articles published on it are resistant to censorship, while keeping readers and journalists anonymous at the same time [14]. Among the audience are magazine/article readers which value high quality journalism free from censorship. Blockchain enables innovative products and services.

\subsection{State government}

State government is often complicated and unnecessarily complex for citizens. Blockchain could improve the user-friendliness of voting and justice systems and make them more accessible to citizens in remote parts of a country. This could lead to an increase in participation, which can result in better overall decision making.

4.4.1 E-voting. Voting is considered the foundation of any successful democracy and must therefore be accessible and secure for all eligible citizens [49]. However, today's most common paper-based voting systems have two major problems: they are not scalable and are reliant on the procedural security of officials conducting their jobs properly and honestly [49]. Additionally, when assisted by electronic voting machines, security vulnerabilities can lead to election rigging and fraud [49]. Using blockchain, these issues can be solved. It might offer a massively scalable solution by providing secure and fraud-proof digital voting [49]. Voters are among the target audience of these solutions. Blockchain will lead to improved customer interaction convenience, and product and service quality.

\subsection{Supply chain}

The supply chain is the third most referenced sector in the final papers. Distrust among partners, transaction fees and restrictions plague consumers in marketplaces and they have no insight into the supply chain of their valuable products. Blockchain could revolutionize both, as it has the potential to minimize transaction fees, remove restrictions in marketplaces and create new ways for consumers to gain insight into the way their products are produced.

4.5.1 Marketplaces. Marketplaces provide an infrastructure where physical as well as digital goods and services can be traded. For such marketplaces, consumer behavior is largely determined by their trust in the intermediary [50], [51]. Marketplaces such as Amazon charge fees and sometimes even restrict offered products. Because the "trust problem" is fundamentally solved by blockchain, marketplaces built upon it are trusted. In comparison to traditional marketplaces, there is no central authority that is running the marketplace, allowing everyone with internet access to set up a shop and participate [26] without being subject to fees or restrictions. Finally, payment transaction fees are decreased and the global reach is increased [26]. Traders of marketplaces are targeted. They will receive customer tailored solutions which perfectly match their needs.

4.5.2 Product authenticity and active participation. The information of how a product is created and delivered is often not accessible for consumers. The underlying supply chains are opaque and hidden to the end consumer [27]. Consumers have to trust their products with no means to verify. Usually it makes no difference: the hamburger a consumer bought on the market will be safe to eat. But occasionally, consumers get a glimpse of mad cow disease [14]. Blockchain helps track the origin and transformations undergone in the supply chain [52]. It further enables active participation in creation of the product, allowing the consumer to receive promotions and discounts in exchange for their help [27], [53]. Consumers of valuable assets are the main audience. Main effects are rooted in improved customer interaction convenience.

\subsection{Private transportation}

In private transportation, possible future blockchain applications combined with intelligent transportation systems could further build on the benefits car shar- 
ing services introduced to consumers over the last years. It could eliminate the central authorities, giving consumers and transportation providers ways to directly settle on a price. This would result near nonexistent transaction fees and an improvement in general consumer transportation coverage.

\section{Discussion}

In this section, we reflect on the presented findings. Consumers that engage with blockchain solutions experience the abolition of intermediaries resulting in more trust, less corruption, smaller fees, faster processes, better access, more granularity and less censorship in the products and services. It allows for more efficient trades and interaction between consumers and producers.

The distribution of the sectors, based on the numbers of references in the final papers, is uneven. Three main sectors, namely the financial (33\%), records management (25\%) and supply chain (20\%) dominate. This can be explained as follows: The financial sector was one of the first to adopt blockchain, as the technology emerged and blockchain keeps expanding in this field. Application of blockchain in records management is likely driven by the immutability characteristic of blockchain, resulting in records that cannot be tampered with. This creates an advantage over traditional systems. Finally, in supply chains blockchain solves the problem of missing trust between large numbers of untrusted stakeholders: Many (to each other often unknown) stakeholders participate in global supply chain processes and blockchain could help restore trust between parties.

Targeted consumers include a broad range, from bank customers to consumers with digital identities. It has been found that many consumers will be affected by blockchain-based products and services. The categorization of the different key benefits of [9] revealed that most subsectors could be accurately described using one of the four main benefits. This supports the choice of the framework of [9]. Surprisingly, even though blockchain is nascent, we could not identify any other category that could supplement the framework of [9]. This suggests that even though blockchain is a new technology, the benefits remain similar to the ones introduced by digitalization. Summarizing the results, we show that consumers should expect the biggest influence of the blockchain in innovative products and services as it solves the fundamental problem of trust and enables smart contracts. Because the blockchain is fast and efficient, the second most identified benefit is the improved product and service quality. As one might expect, the efficiency of the blockchain will enable businesses to provide faster and more high-quality solutions.

For most sectors, there are existing blockchain solutions. These are ready to be used by consumers today. In case of the financial sector, there are many accessible solutions, and other subsectors like sealing, marketplaces and product authenticity and active participation also provide consumers with the opportunity to engage right now. Our interviews with blockchain experts confirmed the applications of blockchain in these sectors. Interestingly, there were also subsectors mentioned that were not found in the literature review. Those cover trade finance and logistics, where blockchain could improve the process of financing international trade flows and performance management, where the transparency of blockchain could be beneficial.

The following question remains: if there are many benefits for consumers to use blockchain-based solutions, then why does the average consumer interact very little, or not at all, with such services and products? Based on the literature and our interviews, it seems that there are three major challenges blockchain must overcome to gain wide adaptation among consumers: technical, institutional and human.

The first challenge blockchain must overcome is of technical nature. In order for a consumer to perform a first transaction on a blockchain (e.g. Bitcoin), the consumer first needs to download the entire set of existing blockchains and validate those before executing the transaction [28]. This process can take hours or longer [28]. According to our interviews, this results in a complex process and cannot be considered user-friendly, which is what consumers seek.

The second challenge blockchain must overcome is of institutional nature. Some governments appear restricting towards new blockchain services, such as China where the central bank once disabled withdrawal of Bitcoin. On the flipside, there are also governments such as Estonia, which promote and integrate blockchain for nation-wide services for citizens.

The third challenge is rooted in consumers themselves. Humans are not used in the habit of backing up their money such as Bitcoin on a flash drive or a second device, or even encrypting their storage [14]. There is a need for behavior change deeper than netiquette, because with greater freedom - better privacy, stronger security and independence from third parties - comes greater responsibility [14]. There is no bank employee that provides help when consumers lose access to their private key of a Bitcoin wallet. Storing such a private key could also make the devices of a consumer a desirable target for hackers trying to hijack it, one interviewee said. This could result in a feeling of uneasiness in the minds of consumers. 
While most of the applications of blockchain in this paper suggest positive outcomes for consumers, there are also several pitfalls which must be mentioned. First, the blockchain never forgets. This is in contradiction with the long tradition in finance of obliterating records [14]. Once a mistake is made, it is stored forever. Second, with smart contracts comes the problem of the lack of legal recourse: even though smart contracts act automatically and perfectly rational, the humans who create them do not [14]. How will such cases be settled in court, if there is a disagreement? Finally, as the blockchain is public by default, does this mean that data aggregation companies like Google have easy access to the totality of a consumers' data? It is possible, that unlike the blockchain promises to return the control over their data back to consumers, in the end it hands it over to data aggregation companies on a silver plate.

Finally, one should consider that the topic of blockchain is currently a hype, in both academic and industrial fields. While a lot of new and innovative firms are being created, it is not guaranteed that all of them will succeed and flourish. As with every hype, there is a good chance that this excitement will fade and many solutions will cease to operate.

\section{Conclusion, Limitations and Outlook}

Our research delivers insights into how blockchain affects consumers. These insights are valuable for future research from both a scientific and practical point of view, as they will help other researchers to understand the current state of research, and practitioners to design more user-oriented solutions. We find that there are many existing blockchain solutions waiting to be utilized by consumers. However, it is questionable how many of these solutions will continue to operate in the future. Further, we argue that most effects of introduction of blockchain-based products and services create benefits for consumers, allowing them to have more control and power over what and how they consume. However, we also find that there currently is a low number of consumers that use blockchain solutions. There are technical, institutional and human challenges blockchain must overcome before it can achieve wide consumer adaptation. Finally, we warn of potential pitfalls of blockchain: the blockchain never forgets mistakes, leaves no room for human errors and raises concerns on the protection of personal data.

We should admit the following limitations. The study is based on scientific and practical literature. While scientific literature can be considered mainly objective pieces of work, practical literature cannot: companies might exaggerate the positive effects of the blockchain to reach their own competitive goals. This may lead to exaggeration of benefits and simultaneous downplay of challenges of the blockchain, creating subjectivity for these materials. Further, application of frameworks different from [9] would likely have led to additional results and insights. Lastly, the list of blockchain solutions is not comprehensive and only displays a subset of the solutions currently available.

We expect the blockchain to go through slow acceptance of the public at first. The population needs to accustom to the new technology and change their behavior respectively. However, once the different services and models of the blockchain have grown to a critical size, and the benefits are understood by the population, we might see an exponential rise of consumer usage due to the network effects often used in combination with blockchain. Our research yields new research avenues: the technical, institutional and human challenges of blockchain need to be solved and pitfalls must be avoided. Future research could investigate whether and how we can overcome these challenges and pitfalls. Furthermore, researchers should analyze additional benefits and potential dangers of blockchain. Special emphasis should lie on the latter, as they have the potential to hinder blockchain-based systems.

\section{References}

[1] S. Nakamoto, "Bitcoin: A peer-to-peer electronic cash system," 2008.

[2] J. George, "Growing \& changing trends in consumer behavior," in Electrical, Electronics, and Optimization Techniques (ICEEOT), International Conference on, 2016, pp. 4804-4809.

[3] E. Piccinini, R. W. Gregory, and L. M. Kolbe, "Changes in the Producer-Consumer Relationship-Towards Digital Transformation.," in Wirtschaftsinformatik, 2015, pp.

1634-1648.

[4] N. Corrocher and A. Ordanini, "Measuring the digital divide: a framework for the analysis of cross-country differences," J. Inf. Technol., vol. 17, no. 1, pp. 9-19, 2002. [5] A. Bharadwaj, O. A. El Sawy, P. A. Pavlou, and N. V. Venkatraman, "Digital business strategy: toward a next generation of insights," 2013.

[6] S. Aral, C. Dellarocas, and D. Godes, "Introduction to the special issue-social media and business transformation: a framework for research," Inf. Syst. Res., vol. 24, no. 1, pp. 3-13, 2013.

[7] G. Oestreicher-Singer and L. Zalmanson, "Content or community? A digital business strategy for content providers in the social age," 2012.

[8] B. Bloching and E. Wege, "Wer teilt, gewinnt." 2014. [9] A. Neumeier, T. Wolf, and S. Oesterle, "The Manifold Fruits of Digitalization-Determining the Literal Value Behind," 2017. 
[10] E. K. Clemons, "How information changes consumer behavior and how consumer behavior determines corporate strategy," J. Manag. Inf. Syst., 2008.

[11] Q. K. Nguyen, "Blockchain-A Financial Technology for Future Sustainable Development," in Green Technology and Sustainable Development (GTSD), 2016, pp. 51-54. [12] Y. Yuan and F. Y. Wang, "Towards blockchain-based intelligent transportation systems," in 2016 IEEE 19th International Conference on Intelligent Transportation Systems (ITSC), 2016, pp. 2663-2668.

[13] Y. Yuan and F. Y. Wang, "Blockchain: the state of the art and future trends," Acta Autom. Sin., vol. 42, no. 4, pp. 481-494, 2016.

[14] D. Tapscott and A. Tapscott, Blockchain Revolution: How the Technology Behind Bitcoin Is Changing Money, Business, and the World. Penguin, 2016.

[15] K. Silverberg, C. French, and Ferenzy, "Getting Smart: Contracts on the Blockchain," 2016.

[16] J. Yli-Huumo, D. Ko, S. Choi, S. Park, and K. Smolander, "Where Is Current Research on Blockchain Technology?-A Systematic Review," PloS One, vol. 11, no. 10, p. e0163477, 2016.

[17] J. Lindman, V. K. Tuunainen, and M. Rossi, “Opportunities and Risks of Blockchain Technologies-A Research Agenda," 2017.

[18] Y. Levy and T. J. Ellis, "A systems approach to conduct an effective literature review in support of information systems research," Informing Sci. Int. J. Emerg. Transdiscipl., vol. 9, no. 1, pp. 181-212, 2006.

[19] J. Beel and B. Gipp, “Google Scholar's ranking algorithm: an introductory overview," in Proceedings of the 12th International Conference on Scientometrics and Informetrics (ISSI'09), 2009, vol. 1, pp. 230-241.

[20] Google Scholar, "About Google Scholar," 2017. [21] M. Jun and S. Cai, "The key determinants of internet banking service quality: a content analysis," Int. J. Bank Mark., vol. 19, no. 7, pp. 276-291, 2001.

[22] F. Holotiuk, F. Pisani, and J. Moormann, "The Impact of Blockchain Technology on Business Models in the Payments Industry," 2017.

[23] S. Agyepong and H. Twinomurinzi, "FACILITATING FINANCIAL INCLUSION USING ICT: LESSONS FROM M-PESA AND E-ZWICH," 2016.

[24] X. Yue, H. Wang, D. Jin, M. Li, and W. Jiang, "Healthcare data gateways: found healthcare intelligence on blockchain with novel privacy risk control," J. Med. Syst., vol. 40, no. 10, p. 218, 2016.

[25] M. Hancock and E. Vaizey, "Distributed Ledger Technology: Beyond Blockchain," UK Gov. Off. Sci., 2016. [26] D. Wörner, T. Von Bomhard, Y.-P. Schreier, and D. Bilgeri, "The Bitcoin Ecosystem: Disruption Beyond Financial Services?," 2016.

[27] M. Pilkington, "Blockchain technology: principles and applications," Brows. Download This Pap., 2015.

[28] M. Crosby, P. Pattanayak, S. Verma, and V. Kalyanaraman, "Blockchain technology: Beyond bitcoin," Appl.

Innov., vol. 2, pp. 6-10, 2016.

[29] J. Mattila and others, "The Blockchain PhenomenonThe Disruptive Potential of Distributed Consensus Architectures," The Research Institute of the Finnish Economy, 2016.
[30] M. Swan, Blockchain: Blueprint for a new economy. O'Reilly Media, Inc., 2015.

[31] D. Mark, "Medici Ventures invests in Latin American bitcoin startup Ripio," GlobeNewswire News Room, 26Apr-2017.

[32] P. Vigna, "BitBeat: Bitcoin-Startup BitPesa Expands Into Nigeria, Uganda," WSJ, 09-Nov-2015.

[33] Starbase, “Starbase," Starbase. [Online]. Available: https://starbase.co.

[34] Rizzo, "Blockchain Prediction Market Augur Enters Beta," CoinDesk, 14-Mar-2016.

[35] M. Mettler, "Blockchain technology in healthcare: The revolution starts here," in e-Health Networking, Applications and Services (Healthcom), 2016 IEEE 18th International Conference on, 2016, pp. 1-3.

[36] P. Meeusen, "Insurers and reinsurers launch Blockchain initiative | Swiss Re - Leading Global Reinsurer," 2016.

[37] N. Rückeshäuser, "Do We Really Want BlockchainBased Accounting? Decentralized Consensus as Enabler of Management Override of Internal Controls," 2017.

[38] The vDice Team, "vDice - Defining Blockchain Gambling on Ethereum," The vDice Team, 20-Nov-2016. . [39] J. Redman, "Decentralized eSports Platform FirstBlood Raises \$5.5M in Minutes," Bitcoin News, 26Sep-2016.

[40] S. Wagenknecht, "Steemit: Eine Kombination aus Blockchain und Social Media," BTC-ECHO, 15-Aug-2016. [41] J. Redman, "Blockchain Startup DECENT Launches Web Prototype," Bitcoin News, 06-Nov-2016. .

[42] DECENT, "DECENT Development Plan \& Roadmap,” DECENT, 2016. [Online]. Available: https://decent.ch/en/blog/decent-development-planroadmap/.

[43] S. Higgins, "Nasdaq Declares Blockchain Voting Trial a 'Success' - CoinDesk," 2017.

[44] F. Caiazzo and M. Chow, "A Block-Chain Implemented Voting System," 2016.

[45] F. Ast and A. Sewrjugin, "The CrowdJury, a Crowdsourced Justice System for the Collaboration Era," 2015.

[46] Everledger, "Everledger | A Digital Global Ledger." [Online]. Available: https://www.everledger.io/.

[47] N. Killbride, "Self-Driving Vehicles and Smart Contracts via the Blockchain," CryptoCoinsNews, 04-Jan-2016. [48] I. Allison, "UBS, innogy and ZF collaborate on blockchain wallets for cars," International Business Times $U K$, 03-Jan-2017.

[49] R. Osgood, “The Future of Democracy: Blockchain Voting," 2016.

[50] S. Jarvenpaa and R. Teigland, "Introduction to Trust, Identity, and Trusted Systems in Digital Environments Minitrack," 2017.

[51] I. B. Hong and H. Cho, "The impact of consumer trust on attitudinal loyalty and purchase intentions in B2C emarketplaces: Intermediary trust vs. seller trust," Int. J. Inf. Manag., vol. 31, no. 5, pp. 469-479, 2011.

[52] V. Buterin, "A next-generation smart contract and decentralized application platform," White Pap., 2014. [53] R. Williams, "How Bitcoin Tech Could Make Supply Chains More Transparent," 2015. 